УДК $551.212+552.3$

\title{
ПЕРВЫЕ ДАННЫЕ О СОСТАВЕ ПРОДУКТОВ ТРЕЩИННОГО ТОЛБАЧИНСКОГО ИЗВЕРЖЕНИЯ им. 50-летия ИВиС (КАМЧАТКА)
}

\author{
(C) 2013 г. А. О. Волынец, Д. В. Мельников, А. И. Якушев \\ Представлено академиком Е.И. Гордеевым 15.04.2013 г.
}

Поступило 15.05.2013 г.

DOI: $10.7868 / \mathrm{S} 0869565213280219$

Толбачинский Дол - южная часть крупнейшей на Камчатке зоны моногенного вулканизма, пересекающей Ключевскую группу вулканов - активно формировался в голоцене [1,2]. Последний эпизод активизации Дола зафиксирован в 19751976 гг. Это извержение известно под названием Большого Трещинного Толбачинского извержения (БТТИ) и хорошо изучено $[1,2]$. Спустя 37 лет, 27 ноября 2012 г. на Толбачинском Долу началось новое извержение трещинного типа, получившее название Трещинного Толбачинского извержения имени 50-летия ИВиС (ТТИ-50). В нашей статье представлены первые данные, характеризующие состав пород нового извержения, и предпринята попытка рассмотреть эволюцию состава вулканитов за первые два месяца работы ТТИ-50.

Извержение началось с раскрытия трещины, фонтанирования и излияния лавы в прорыве

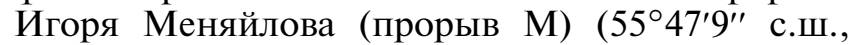
$160^{\circ} 19^{\prime} 39^{\prime \prime}$ в.д., высота 1900 м) (рис. 1). Несколько позже ниже по склону образовалась трещина про-

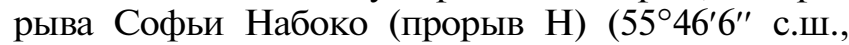
$160^{\circ} 18^{\prime} 59^{\prime \prime}$ в.д., высота 1650 м).

Породы прорыва М представлены субафировыми черными трахиандезибазальтами (табл. 1, pис. 2) с редкими суб- и фенокристаллами Pl, Ol, $\mathrm{Cpx}$, а также их гломеропорфировыми сростками. Микролиты основной массы, обладающей пилотакситовой и гиалопилитовой структурой, представлены главным образом $\mathrm{Pl}$, часто имеющим форму “ласточкин хвост”, и в подчиненном количестве - изометричными кристаллами $\mathrm{Ol}, \mathrm{Px}$, TiMt. В целом особенности микроструктур и тек-

Институт вулканологии и сейсмологии

Дальневосточного отделения

Российской Академии наук,

Петропавловск-Камчатский

Институт геологии рудных месторождений, петрографии, минералогии и геохимии

Российской Академии наук, Москва стур лав начала извержения свидетельствуют об очень быстром поступлении магмы на поверхность. Породы прорыва Н также представлены трахиандезибазальтами, но более основного состава (табл. 1, рис. 2). В них увеличивается количество вкрапленников, появляются более крупные вкрапленники Pl (до 1 см в поперечнике при толщине 1-2 мм) и Оl (до 3 мм в поперечнике). При этом общий облик породы остается субафировым.

Химический состав продуктов извержения приведен в табл. 1 и на рис. 2 , 3. Наиболее богаты $\mathrm{SiO}_{2}$ первые порции лав прорыва М. С декабря, когда активность полностью сосредоточилось в прорыве Н, произошло довольно резкое изменение состава продуктов извержения: содержание $\mathrm{SiO}_{2}$ упало практически на $2 \%$ и оставалось на этом уровне до конца января; при этом выросли значения $\mathrm{MgO}, \mathrm{TiO}_{2}, \mathrm{Mg} \#$ и уменьшились $-\mathrm{K}_{2} \mathrm{O}$, $\mathrm{Na}_{2} \mathrm{O}$ и отношение $\mathrm{K}_{2} \mathrm{O} / \mathrm{MgO}$. Первые порции лав прорыва $\mathrm{H}$ от 2-7 декабря по $\mathrm{Mg}$, содержанию $\mathrm{SiO}_{2}, \mathrm{MgO}$ и щелочей, отношению $\mathrm{K}_{2} \mathrm{O} / \mathrm{MgO}$ могут рассматриваться как промежуточные между лавами прорыва М и более поздними лавами прорыва Н. Состав пород прорыва Н в течение декабря и января оставался практически неизменным; исключение - шлак от 31 декабря, отличающийся пониженными концентрациями $\mathrm{SiO}_{2}, \mathrm{CaO}, \mathrm{K}_{2} \mathrm{O}$ и повышенными - $\mathrm{FeO}$.

Содержание микроэлементов закономерно изменяется в зависимости от валового состава пород. Так, Rb, Ba, Zr, Y коррелируются с содержанием кремнезема положительно, a $\mathrm{Cr}, \mathrm{Ni}, \mathrm{Co}-$ отрицательно. Породы прорыва М имеют несколько более высокие концентрации РЗЭ и других несовместимых микроэлементов, чем породы прорыва $\mathrm{H}$, при одинаковых межэлементных отношениях (рис. 3). Такие особенности вещественного состава могут говорить о связи пород двух прорывов нового извержения с процессами фракционирования единого исходного расплава. Заметный ев- 


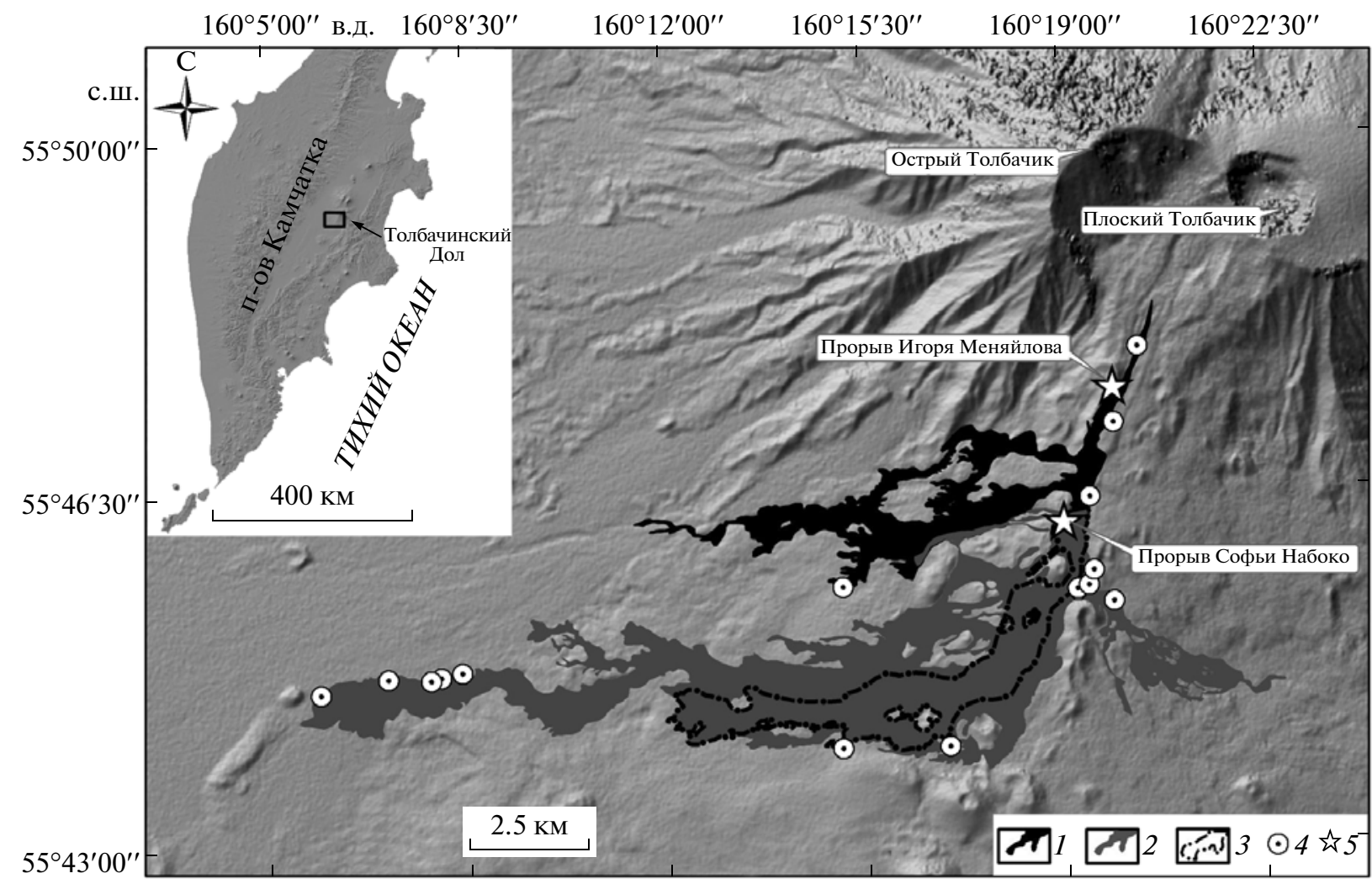

Рис. 1. Схема распространения лавовых потоков ТТИ-50 по состоянию на конец марта 2013 г. 1 - лавовые потоки прорыва Меняйлова; 2 - лавовые потоки прорыва Набоко; 3 - лавовые потоки прорыва Меняйлова, впоследствии в своем большинстве перекрытые лавами прорыва Набоко; 4 - места отбора проб; 5 - центры текущего извержения. Схема составлена на основе дешифрирования космических снимков TERRA ASTER (NASA, JPL), EO-1 ALI (NASA) и по результатам проведения полевых работ. Топографическая основа - ЦMP SRTM X-band (DLR).

ропиевый минимум на диаграмме распределения РЗЭ (не показано) указывает на существенную роль фракционирования плагиоклаза в процессе формирования магм нового извержения.

На рис. 2 видно, что породы ТТИ-50, извергшиеся в ноябре 2012-январе 2013 г., заметно отличаются от ранее изученных вулканических пород Толбачинского Дола. Все породы нового извержения имеют повышенную щелочность и концентрации $\mathrm{TiO}_{2}$, при этом лавы прорыва М являются самыми кислыми разностями из всех ранее извергнутых здесь пород, а лавы прорыва Н, имея кремнекислотность, близкую к продуктам Южного прорыва БТТИ и другим глиноземистым андезибазальтам Дола, отличаются несколько более низкими концентрациями $\mathrm{Al}_{2} \mathrm{O}_{3}, \mathrm{CaO}, \mathrm{MgO}$. Особенные характеристики пород нового извержения вынудили нас искать сходные по типу породы в пределах всей Ключевской группы вулканов, на которую, собственно, и наложена региональная зона Толбачинского Дола. Оказалось, что продукты ТТИ-50 обнаруживают некоторое сходство с высоко-К породами массива Плоские Сопки и попадают в их эволюционные тренды, отличаясь, однако, по ряду элементов, наиболее ярко - по содержанию титана (рис. 2). Андезибазальты ТТИ-50 имеют более высокие концентрации Р3Э, Y, Nb, Hf, Zr, Тa, Ti, чем породы БТТИ; Nb, $\mathrm{Ti}$, Та в них также больше, чем в высоко-К породах массива Плоских Сопок (рис. 3).

Резюмируя изложенное, можно утверждать, что по своим геохимическим характеристикам породы ТТИ-50 являются уникальными для Толбачинского Дола. При этом особенности их состава позволяют предполагать генетическую связь изученных пород с источниками базальтов Южного прорыва БТТИ и глиноземистых базальтов Дола. Различия пород верхнего (М) и нижнего $(\mathrm{H})$ прорывов нового трещинного извержения могут быть связаны с тем, что изливающиеся из них магмы принадлежат разным уровням единой магматической камеры. В прорыве М извергалась прикровельная порция магмы, претерпевшая заметную дифференциацию и, возможно, ассимиляцию вмещающих пород; в прорыве Н, расположенном гипсометрически ниже, начали дренироваться менее фракционированные части магматического очага.

Авторы благодарят Н.В. Горбач, Н.А. Малик, Б. Эдвардса (Benjamin Edwards), А.Б. Белоусова за предоставленные образцы, А.Д. Бабанского - за 
Таблица 1. Представительные анализы пород ТТИ-50, изверженных 27.11.2012-25.01.2013 г.

\begin{tabular}{|c|c|c|c|c|c|c|c|c|}
\hline \multirow{2}{*}{ Компонент } & \multicolumn{8}{|c|}{ Номер образца } \\
\hline & 1 & 2 & 3 & 4 & 5 & 6 & 7 & 8 \\
\hline $\mathrm{SiO}_{2}$ & 53.76 & 54.68 & 52.41 & 52.06 & 51.74 & 50.45 & 51.75 & 51.76 \\
\hline $\mathrm{TiO}_{2}$ & 1.82 & 1.70 & 2.00 & 2.00 & 1.92 & 1.87 & 1.96 & 1.93 \\
\hline $\mathrm{Al}_{2} \mathrm{O}_{3}$ & 16.32 & 16.5 & 15.76 & 15.74 & 16.07 & 15.63 & 16.2 & 16.19 \\
\hline $\mathrm{FeO}^{*}$ & 9.20 & 8.65 & 10.32 & 10.51 & 10.56 & 12.57 & 10.49 & 10.55 \\
\hline $\mathrm{MnO}$ & 0.17 & 0.17 & 0.17 & 0.17 & 0.17 & 0.18 & 0.17 & 0.17 \\
\hline $\mathrm{MgO}$ & 3.37 & 2.98 & 3.81 & 4.02 & 4.1 & 4.18 & 4.13 & 4.15 \\
\hline $\mathrm{CaO}$ & 7.26 & 6.67 & 7.56 & 7.48 & 7.37 & 7.02 & 7.32 & 7.31 \\
\hline $\mathrm{Na}_{2} \mathrm{O}$ & 3.81 & 4.04 & 3.52 & 3.56 & 3.58 & 3.48 & 3.61 & 3.58 \\
\hline $\mathrm{K}_{2} \mathrm{O}$ & 2.45 & 2.64 & 2.48 & 2.41 & 2.37 & 2.31 & 2.38 & 2.36 \\
\hline $\mathrm{P}_{2} \mathrm{O}_{5}$ & 0.69 & 0.77 & 0.6 & 0.66 & 0.7 & 0.68 & 0.7 & 0.7 \\
\hline Сумма & 98.84 & 98.79 & 98.63 & 98.61 & 98.59 & 98.37 & 98.71 & 98.70 \\
\hline $\mathrm{Li}$ & 21.7 & 20.9 & 18.5 & 17.9 & 18.2 & 19.6 & 18.4 & 18.9 \\
\hline $\mathrm{Be}$ & 2.0 & 2.1 & 1.9 & 1.8 & 1.9 & 1.9 & 1.9 & 2.0 \\
\hline $\mathrm{Sc}$ & 27.3 & 25.8 & 30.3 & 29.3 & 28.3 & 27.5 & 26.9 & 27.4 \\
\hline V & 264 & 214 & 260 & 306 & 302 & 286 & 286 & 299 \\
\hline $\mathrm{Cr}$ & 15 & 8 & 20 & 20 & 30 & 79 & 33 & 42 \\
\hline $\mathrm{Co}$ & 26 & 24 & 20 & 27 & 31 & 41 & 33 & 40 \\
\hline $\mathrm{Ni}$ & 11 & 11 & 30 & 40 & 36 & 71 & 32 & 38 \\
\hline $\mathrm{Ga}$ & 19.83 & 21.3 & 21.07 & 21.1 & 20.9 & 21.1 & 20.5 & 20.5 \\
\hline $\mathrm{Rb}$ & 64 & 65 & 62 & 64 & 60 & 56 & 62 & 60 \\
\hline $\mathrm{Sr}$ & 312 & 322 & 312 & 307 & 311 & 274 & 304 & 310 \\
\hline $\mathrm{Y}$ & 52 & 50 & 39 & 43 & 48 & 44 & 50 & 46 \\
\hline $\mathrm{Zr}$ & 257 & 262 & 227 & 245 & 252 & 226 & 252 & 257 \\
\hline $\mathrm{Nb}$ & 9 & 9 & 8 & 8 & 8 & 8 & 8 & 8 \\
\hline Cs & 2.3 & 2.7 & 2.4 & 2.3 & 2.3 & 2.3 & 2.2 & 2.2 \\
\hline $\mathrm{Ba}$ & 571 & 604 & 557 & 553 & 566 & 504 & 554 & 574 \\
\hline $\mathrm{La}$ & 22.3 & 23.7 & 21.7 & 21.5 & 21.2 & 21.2 & 20.6 & 21.4 \\
\hline $\mathrm{Ce}$ & 56.5 & 63.6 & 57.7 & 55.0 & 55.2 & 54.3 & 54.2 & 55.7 \\
\hline $\operatorname{Pr}$ & 7.8 & 8.2 & 7.6 & 7.6 & 7.4 & 7.5 & 7.3 & 7.5 \\
\hline $\mathrm{Nd}$ & 35.7 & 37.7 & 34.4 & 34.8 & 34.5 & 33.7 & 33.8 & 34.8 \\
\hline $\mathrm{Sm}$ & 8.4 & 9.0 & 8.3 & 8.4 & 8.2 & 8.1 & 8.2 & 8.2 \\
\hline $\mathrm{Eu}$ & 2.2 & 2.4 & 2.1 & 2.2 & 2.2 & 2.1 & 2.1 & 2.2 \\
\hline $\mathrm{Gd}$ & 8.6 & 9.0 & 8.1 & 8.3 & 8.2 & 8.1 & 8.2 & 8.2 \\
\hline $\mathrm{Tb}$ & 1.3 & 1.4 & 1.3 & 1.3 & 1.2 & 1.2 & 1.2 & 1.2 \\
\hline Dy & 7.8 & 7.9 & 7.3 & 7.4 & 7.3 & 7.2 & 7.2 & 7.4 \\
\hline Ho & 1.6 & 1.7 & 1.5 & 1.5 & 1.5 & 1.5 & 1.5 & 1.5 \\
\hline $\mathrm{Er}$ & 4.6 & 4.8 & 4.5 & 4.5 & 4.5 & 4.4 & 4.4 & 4.4 \\
\hline $\mathrm{Tm}$ & 0.7 & 0.7 & 0.6 & 0.6 & 0.6 & 0.6 & 0.6 & 0.6 \\
\hline $\mathrm{Yb}$ & 4.4 & 4.5 & 4.1 & 4.1 & 4.1 & 4.0 & 4.0 & 4.1 \\
\hline $\mathrm{Lu}$ & 0.7 & 0.7 & 0.6 & 0.6 & 0.6 & 0.6 & 0.6 & 0.6 \\
\hline Hf & 7.3 & 7.3 & 6.7 & 6.7 & 6.7 & 6.4 & 6.5 & 6.6 \\
\hline $\mathrm{Ta}$ & 0.6 & 0.5 & 0.5 & 0.5 & 0.5 & 0.5 & 0.5 & 0.5 \\
\hline $\mathrm{Tl}$ & 0.1 & 0.1 & 0.1 & 0.1 & 0.1 & 0.1 & 0.1 & 0.3 \\
\hline $\mathrm{Pb}$ & 8.4 & 9.7 & 8.4 & 8.4 & 8.2 & 8.2 & 7.9 & 8.0 \\
\hline Th & 3.7 & 3.2 & 2.7 & 2.8 & 2.7 & 2.9 & 2.7 & 2.8 \\
\hline $\mathrm{U}$ & 1.8 & 2.3 & 2.0 & 2.0 & 1.9 & 2.0 & 1.9 & 2.0 \\
\hline
\end{tabular}

Примечание. Концентрации главных петрогенных оксидов (мас. \%), микроэлементов (г/т). Обр. 1, 2 - прорыв Меняйлова, остальные - прорыв Набоко: 1 - TOLB-1201 (лава, 27.11.2012 г.), 2 - ТМ-08 (лава, 27.11.2012 г.), 3 - ТМ-1 (лава, 02.12 .2012 г.), 4 - ТМ-6 (лава, 10.12.2012 г.), 5 - ТМ-10 (лава, 22.12.2012 г.), 6 - TOLB-1204 (шлак, 31.12.2012 г.), 7 - Tm-14 (лава, 21.01 .2013 г.), 8 - TOLB-1307 (бомба, январь 2013 г.). Анализы главных петрогенных оксидов, V, Cr, Co, Ni, Cu, Zn, Rb, Sr, Y, Zr, Nb, Ba, Pb выполнены в ИГЕМ РАН методом XRF, остальные микроэлементы проанализированы в ИПТМ РАН методом ICP-MS. Bсе $\mathrm{Fe}$ в форме $\mathrm{FeO}$. 


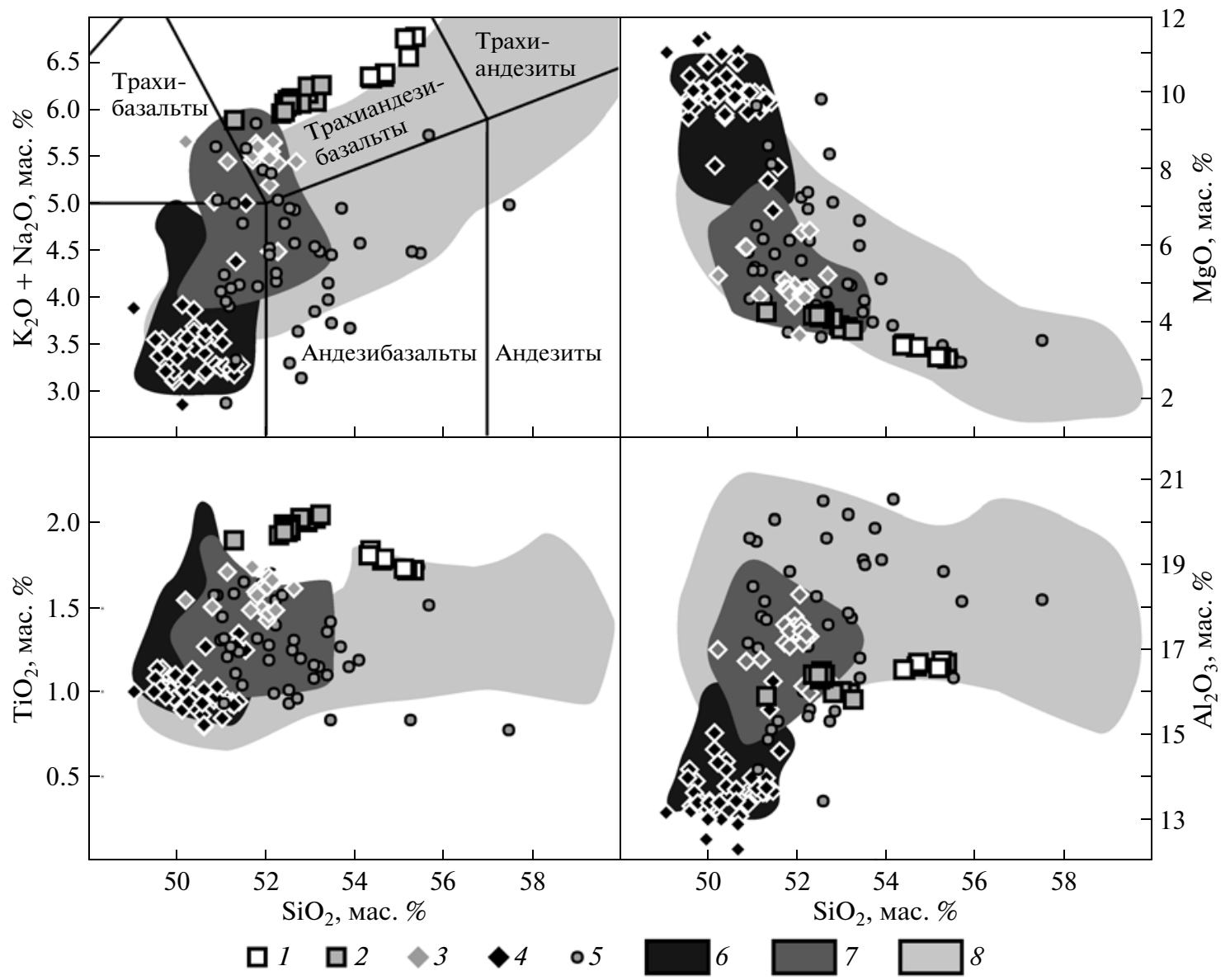

Рис. 2. Вариационные диаграммы пород ТТИ-50. 1, 2 - ТТИ-50: 1 - прорыв М, 2 - прорыв Н; 3, 4- БТТИ: 3 - Южный прорыв, 4 - Северный прорыв; 5 - вулканы Плоский, Острый Толбачики; 6,7 - Толбачинский Дол, породы: 6 - высоко-Mg, 7 - высоко-Al; 8 - породы вулканического массива Плоских Сопок. Составы пород Толбачинского Дола $[1,3-5]$, Острого, Плоского Толбачиков [5, 6], Плоских Сопок [7, 8]. Дискриминационные линии на диаграмме $\mathrm{K}_{2} \mathrm{O}+\mathrm{Na}_{2} \mathrm{O}-\mathrm{SiO}_{2}[9]$

Порода/NMORB

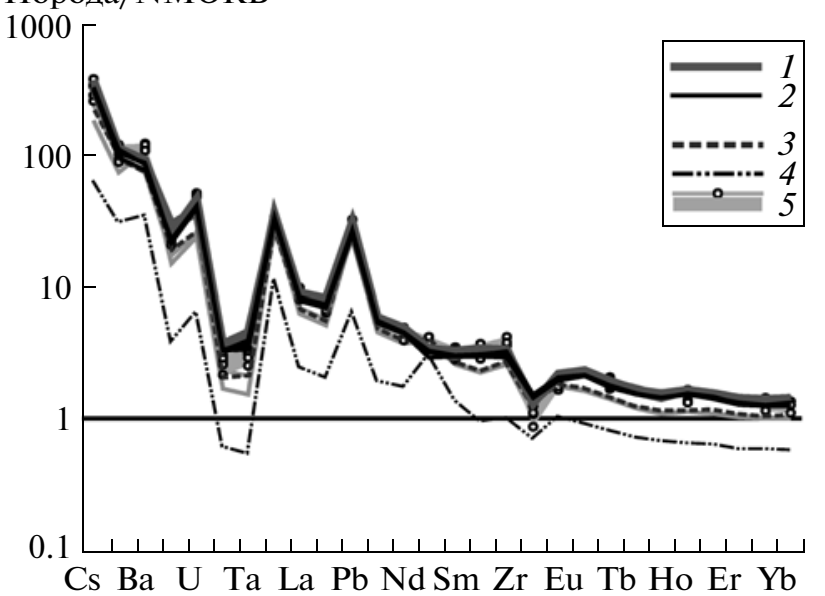

$\mathrm{Rb}$ Th Nb K Ce Pr Sr Hf Ti Gd Dy Y Tm Lu

Рис. 3. Распределение РЗЭ и микроэлементов в породах ТТИ-50. 1, 2- ТТИ-50: 1 - прорыв М, 2- прорыв Н; 3, 4- БТТИ: 3 - Южный прорыв, 4- Северный прорыв; 5 - высоко-К породы вулканического массива Плоских Сопок. Концентрации элементов в NMORB [10]. содействие в аналитических работах, М.М. Певзнер, А.Д. Бабанского - за ценные критические замечания, В.С. Родина - за помощь в пробоподготовке.

Работа выполнена при финансовой поддержке ИВиС ДВО РАН, Программы 9 фундаментальных исследований ОНЗ РАН, Грантов ДВО РАН 12III-A-08-165 (А. Волынец), NSF RAPID 1321648 (Б. Эдвардс).

\section{СПИСОК ЛИТЕРАТУРЫ}

1. Большое трещинное Толбачинское извержение (1975-1976 гг. Камчатка) / Под ред. С.А. Федотова, Г.Б. Флерова, А.М. Чиркова. М.: Наука, 1984. 637 с.

2. Федотов С.А., Балеста С.Т., Двигало В.Н. и др. // Действующие вулканы Камчатки. М.: Наука, 1991. С. 214-274.

3. Волынеи О.Н., Флеров Г.Б., Пополитов Э.И., Абрамов В.А., Петров Л.Л., Щека С.А. // ДАН. 1978. T. 238. № 4. C. $940-943$. 
4. Churikova T., Dorendorf F., Woerner G. // J. Petrol. 2001. V. 42. P. 1567-1593.

5. Portnyagin M., Bindeman I., Hoernle K., Hauff F. // Volcanism and Subduction: The Kamchatka Region. Wash. (D.C.): AGU, 2007. V. 172. P. 203-244.

6. Ермаков В.А., Важеевская А.А. // Бюл. вулканол. станций АН СССР. 1973. № 49. С. 36-43.

7. Чурикова Т.Г., Соколов С.Ю. // Геохимия. 1993. № 10. C. 1439-1448.
8. Чурикова Т.Г. Геохимия и моделирование магматического процесса вулканов Ключевской группы / Дис. канд. геол.-минерал. наук. М.: МГУ. 1993. $155 \mathrm{c}$.

9. A Classification of the Igneous Rocks and Glossary of Terms. Recommendations of the International Union of Geological Sciences on the Systematics of Igneous Rocks / R.W. Le Maitre Ed. Oxford: Blackwell Sci. Publ., 1989. 193 p.

10. Sun S.S., McDonough W.F. // Geol. Soc. London Spec. Publ. 1989. V. 42. P. 313-345. 